\title{
Editorials
}

\section{Disentangling associations between poverty at various levels of aggregation and mental health}

\author{
MARJAN DRUKKER, NICOLE GUNTHER, JIM VAN OS
}

\begin{abstract}
The present editorial discusses whether socioeconomic status of the individual and of the neighbourhood could be important in prevalence, treatment and prevention of psychiatric morbidity. Previous research showed that patients diagnosed with mental disorders are concentrated in socioeconomically disadvantaged areas. This could be the result of (1) an association between individual socioeconomic status and mental health, (2) an association between neighbourhood socioeconomic status and mental health, or (3) social selection. Research disentangling associations between individual and neighbourhood socioeconomic status on the one hand and mental health outcomes on the other, reported that neighbourhood socioeconomic disadvantage was associated with individual mental health over and above individual-level socioeconomic status, indicating deleterious effects for all inhabitants both poor and affluent. In conclusion, subjective mental health outcomes showed stronger evidence for an effect of neighbourhood socioeconomic status than research focussing on treated incidence. Within the group of patients, however, service use was higher in patients living in disadvantaged neighbourhoods. Social capital was identified as one of the mechanisms whereby neighbourhood socioeconomic disadvantage may become associated with observed reductions in mental health. After controlling for individual socioeconomic status, there is evidence for an association between neighbourhood socioeconomic status and objective as well as subjective mental health in adults. Evidence for such an association in young children is even stronger.
\end{abstract}

\section{INTRODUCTION}

Mental disorders are concentrated in socioeconomically disadvantaged urban areas and individuals with psychiatric morbidity have lower socioeconomic status (Reijneveld \& Schene, 1998). The association between poor mental health and lower socioeconomic status can be the result of several processes. The causation hypothesis indicates that lower individual or neighbourhood lower socioeconomic status causes mental health disorder, whereas the selection hypothesis suggests that patients diagnosed with mental disorders have drifted into lower individual or area socioeconomic status (Wiersma et al., 1983; Dohrenwend et al., 1992).

Socioeconomic status has been associated with both objective (Drukker et al., 2004a; Tello et al., 2005) and subjective mental health outcomes (Aneshensel \& Sucoff, 1996; Xue et al., 2005; Drukker et al., 2003). Subjective mental health includes perceptions of a sub-

\footnotetext{
Address for correspondence: Dr. M. Drukker, Department of Psychiatry and Neuropsychology, Maastricht University, PO BOX 616 (Vijverdal), 6200 MD Maastricht (The Netherlands).

Fax: ++31-43-3688689

E-mail: marjan.drukker@sp.unimaas.nl

Declaration of Interest: None
}

ject expressed as measures such as perceived mental health and quality of life, whereas objective mental health is based on objective criteria, such as mental health service consumption and DSM IV diagnoses made by clinicians. For example, individual level socioeconomic status has been associated with the rate of schizophrenia, although the direction of this association was inconsistent (Eaton, 1974; Turner \& Wagenfeld, 1967; Dunham, 1971; Faris \& Dunham, 1939; Hare, 1956; Giggs, 1986; Wiersma et al., 1983; Jones et al., 1994; Dohrenwend et al., 1992). In these early studies, socioeconomic status at the area level was included as a proxy for individual-level socioeconomic status and studies referred to each other without distinguishing between the use of individual level and area level exposures. Only recently, these two measures of socioeconomic status were identified as two different constructs. Although individual and neighbourhood characteristics are necessarily correlated, correlations are from unity indicating likely non-overlapping constructs. Even so, the two concepts are rarely included in the same set of analyses with the aim of assessing their separate and individual effects (Drukker et al., 2006c).

The present editorial discusses whether socioeconomic status of the individual and of the neighbourhood could be important in the prevalence, treatment and prevention of mental health outcomes. 


\section{INDIVIDUAL SOCIOECONOMIC STATUS}

Individual socioeconomic status refers to the position on the socioeconomic ladder of persons or families (Van Berkel-Van Schaik \& Tax, 1990). In terms of material wealth, individuals with a low socioeconomic status are poorer and individuals with a high socioeconomic status are more affluent. Usually, socioeconomic status is a family-level measure and children and adolescents are rated the same status of poverty/affluence as their parents. However, material wealth alone is not the only indicator of socioeconomic status. Thus, educational status, occupational status and income were identified as the three main indicators of socioeconomic status in a Western European country (Van Berkel-Van Schaik \& Tax, 1990).

Early studies on the association between socioeconomic status and mental health mainly focussed on schizophrenia and psychotic disorders. The direction of the association was inconsistent with associations in the direction of both low socioeconomic status (Eaton, 1974; Turner \& Wagenfeld, 1967; Dunham, 1971; Faris \& Dunham, 1939; Hare, 1956; Giggs, 1986) or high socioeconomic status (Wiersma et al., 1983; Jones et al., 1994; Mäkikyrö et al., 1997; Dohrenwend et al., 1992). This inconsistency may result in part depending on the moment of measurement of socioeconomic status in the life course of the individual. Studies measuring socioeconomic status before the onset of illness e.g. socioeconomic status of the parents (Mäkikyrö et al., 1997) or social class at birth (Jones et al., 1994) reported an association between high social class and schizophrenia. This contrasts with some studies using current social status in patients (Eaton, 1974; Giggs, 1986; Faris \& Dunham, 1939). As a consequence of the disease, subjects drop out of school, cannot find a job, or are fired because of malfunctioning and, therefore, do not achieve social class of origin (Wiersma et al., 1983). Therefore, studies measuring current social class (Eaton, 1974) or using current neighbourhood residence as a proxy for social class (Giggs, 1986; Faris \& Dunham, 1939) showed an association between low social class and schizophrenia. However, not all studies are in line with this explanation. For example, one study (Turner \& Wagenfeld, 1967) reported an association between schizophrenia and low socioeconomic status of the father, but the association with patients' socioeconomic status was stronger and higher rates of schizophrenia were reported in an advantaged ethnic group compared to a disadvantaged group (Jews of European background vs Jews of North-African background) (Dohrenwend et al., 1992).
The mechanism of downward social mobility as a consequence of the disease may also play a role in the association between socioeconomic status and other severe mental illness outcomes. For example, lower material standards of living have been associated with common mental disorder (Weich \& Lewis, 1998) and disadvantaged ethnic group has been associated with female rate of depression and male rate of antisocial personality and substance abuse (Dohrenwend et al., 1992). In addition, it has been reported that suicide rates are higher in groups of unemployed or permanently sick (Lewis \& Sloggett, 1998). A Belgium study on psychiatric admissions showed that individuals with a lower socioeconomic status are underrepresented in psychiatric hospitals, but are more frequently admitted through compulsory admission and stay in wards for more severe patients (Lorant $e t$ al., 2003). Thus, it seems that these poorer patients experience more barriers to use mental health services, so that only the more severely ill persons causing social disruption or being a danger for themselves or society end up in (long-term) psychiatric care. This is in line with an Italian case-register study reporting that socioeconomic status was lower in cases that had a once-only contact with psychiatric services than patients who were longer in care (Rossi et al., 2005).

\section{DISENTANGLING INDIVIDUAL FROM NEIGHBOURHOOD SOCIOECONOMIC STATUS: SUBJECTIVE MENTAL HEALTH AND PSYCHOPATHOLOGY}

Neighbourhood socioeconomic status is a primary concept of the quality of the neighbourhood social and structural environment. A very low neighbourhood socioeconomic status is synonymous with neighbourhood socioeconomic disadvantage, neighbourhood poverty, and neighbourhood socioeconomic deprivation. It has been operationalised by an array of social indicators that characterize a so-called "underclass" (Wilson, 1987; Kasarda, 1993). This measure is usually composed of objective indicators, such as the proportion of unemployed, proportion receiving welfare, ethnic composition, and mean income. Individual and neighbourhood socioeconomic status are two different constructs and neighbourhood socioeconomic disadvantage can have deleterious effects for all residents of an area, both poor and affluent (Leventhal \& Brooks Gunn, 2000; Dalgard \& Tambs, 1997; Sloggett \& Joshi, 1994; Diez Roux et al., 2001).

In the 1990s, multilevel regression analyses techniques were developed so that it is now possible to 
include measures of individual and neighbourhood socioeconomic status in one regression model in order to disentangle the associations of these 2 constructs with mental health outcomes (Snijders \& Bosker, 1999).

Using these techniques, neighbourhood socioeconomic status has been associated with subjective mental health and behavioural problems (Drukker et al., 2003; Aneshensel \& Sucoff, 1996; Schneiders et al., 2003; Kalff et al., 2001; Drukker \& Van Os, 2003), over and above individual differences in socioeconomic status. One study even showed a longitudinal association between neighbourhood socioeconomic status and changes in behavioural problems and mental health over a two-year period (Xue et al., 2005). However, several other studies did not show associations between neighbourhood socioeconomic status on the one hand and common mental disorder and depression on the other, or reported that area differences could be explained by individual-level socioeconomic status (Reijneveld \& Schene, 1998; Weich et al., 2003; Henderson et al., 2005).

\section{MECHANISMS OF THE ASSOCIATION BETWEEN NEIGHBOURHOOD SOCIOECONOMIC DISADVANTAGE AND MENTAL HEALTH}

Several mechanisms have been suggested explaining why neighbourhood socioeconomic disadvantage can affect the individual (Leventhal \& Brooks Gunn, 2000; Jencks \& Mayer, 1990). First, resources, such as green facilities, day care, parking places, social activities, employment opportunities and other institutional resources, may be more scarce in poor neighbourhoods, leading to stress because of competition for these resources (Leventhal \& Brooks Gunn, 2000; Jencks \& Mayer, 1990). Second, in residentially stable poor neighbourhoods in particular, residents may feel trapped and powerless in a dangerous and frightening place (Ross et al., 2000). Furthermore, problem behaviour can also be copied from deviant peers (Leventhal \& Brooks Gunn, 2000).

Another mechanism, mediation of social capital, has specific interest. Neighbourhood social capital has been defined as the availability of social resources, social support and social control that neighbourhood residents can count on (Drukker et al., 2006b). This measure has frequently been associated with the mental health of the source population (De Silva et al., 2005; McKenzie et al., 2002; Harpham \& McKenzie, 2006). It has been shown that poverty, heterogeneity and mobility undermine neighbourhood networks and social ties, contributing to a breakdown in social capital (Warner \& Rountree, 1997). In addition, the social disorganisation theory describes that collective efficacy is lower in residents of disadvantaged neighbourhoods, resulting in reduced efforts of residents to invest in the neighbourhood environment and thus in low levels of social capital (Shaw \& McKay, 1969; Sampson \& Morenoff, 1997; Markowitz et al., 2001). Unfortunately, it was not possible to unravel the effects of neighbourhood socioeconomic disadvantage and social capital in some recent studies, due to the high correlations between these neighbourhood variables (Drukker et al., 2003). However, perceptions of neighbourhood cohesion and cosiness (aspects of social capital) were identified as mediators in the association between neighbourhood socioeconomic status and subjective mental health based on the SF36 (a quality of life questionnaire, short form of the Medical Outcome Study questionnaire) (Drukker \& Van Os, 2003).

\section{TREATED PSYCHIATRIC MORBIDITY}

Population measures of quality of life and mental health may yield different results than more objective measures of mental health service use (or: treated psychiatric morbidity). In the psychiatric service use literature, the importance of neighbourhood socioeconomic disadvantage has also been identified (Tansella et al., 1993; Driessen et al., 1998; Tello et al., 2005; Boydell et al., 2001) paving the way for studies disentangling neighbourhood socioeconomic status from individual socioeconomic status. Two types of research are of particular interest.

First, several studies reported that the association between neighbourhood socioeconomic status and the proportion of persons using psychiatric services was reduced to non-significance after controlling for individual level confounders (in various groups of patients: all diagnoses, schizophrenia service use, depression and substance abuse) (Drukker et al., 2006c; 2004a; Silver et al., 2002). However, the latter study hypothesized that this could also be the result of over-control for individual variables (Silver et al., 2002; Sampson et al., 2002), which one author has referred to as the "fallacy of the ecological fallacy" (Schwartz, 1994). Two other studies showed the importance of the neighbourhood in relation to mental health in children. First, neighbourhood poverty was associated with the proportion of children using psychiatric services, over and above effects of individual socioeconomic status, but only when social capital in the neighbourhood was low (Van der Linden et al., 2003). Second, a study on behavioural problems in young children (aged 
3-4.5 years) reported that children in poor neighbourhoods had more behavioural problems when parents knew more neighbours (i.e. high social capital) (Caughy et al., 2003), suggesting a mechanism whereby higher social capital enhanced the spread of improper behaviour, that was common in disadvantaged neighbourhoods. On the other hand, both studies (Van der Linden et al., 2003; Caughy et al., 2003) did report a negative association between neighbourhood poverty and child outcomes. The combined results of the above studies agree with the hypothesis that neighbourhood characteristics are more important in young children than in secondary school children and adults, because young children spent more time in the neighbourhood, while secondary school children (12 years and older) and adults spent more time outside the neighbourhood of residence (Drukker et al., 2006a). More research on the joint effects of neighbourhood social capital and socioeconomic status in children, including effect modification, is needed, but often collinearity between these two constructs is a problem, thus impeding the possibility to disentangle effects of several neighbourhood characteristics (Drukker et al., 2003).

Second, it has been suggested that the quantity of service consumption in those with a treated psychiatric disorder is associated with neighbourhood socioeconomic status. Thus, neighbourhood socioeconomic disadvantage was associated with total psychiatric service consumption for any psychiatric disorder in one study, albeit statistically imprecise by conventional alpha (Drukker $e t$ al., 2004a). On the other hand, service use in the group of patients with the most severe disorder, schizophrenia, was not (Drukker et al., 2006c).

The proportion of psychiatric service use in a population is influenced by three factors: (1) illness severity and prognosis: some patients who use mental health services are more severely ill and have more needs for care; (2) help-seeking behaviour: some patients do not search help, although severely ill, or their need for care is not recognised when contacting general practitioners or other physicians and they may, therefore, not receive the care they need; (3) selection into treatment: some patients may receive care that they do not need (over met needs) (Driessen et al., 1998). These three factors may explain the findings on the quantity of service consumption described above. Thus, the (statistically imprecise) association between neighbourhood socioeconomic disadvantage and total quantity of service consumption for any psychiatric disorder may be a consequence of the severity of the psychiatric disorder, but could also be the result of differences in help-seeking behaviour or treatment selection.
In sum, in adults there is only limited evidence that neighbourhood socioeconomic status impacts on proportion and quantity of service use. In children, evidence for such an association is stronger. These associations (in adults and children) can be the result of illness severity and prognosis, but also of help-seeking behaviour or selection into treatment.

\section{CONFLICTING INDIVIDUAL AND NEIGHBOURHOOD SOCIOECONOMIC STATUS}

A previous study hypothesized that low neighbourhood socioeconomic status has stronger effects on the mental health of poor residents than affluent residents, because poor people may be more dependent on local facilities, but the analyses presented did not show evidence in this direction (the authors suggested a larger study) (Stafford \& Marmot, 2003). Contradictorily, it has been reported that self-esteem of poor adolescents living in a poor neighbourhood increased more over a two-year follow-up period than self-esteem of other poor adolescents (Drukker et al., 2006a). Thus, while the first paper (Stafford \& Marmot, 2003) hypothesized that poor people are worse off in poor neighbourhoods, the second (Drukker et al., 2006a) suggested that they are better off among peers with similar characteristics, in particular as regards socioeconomic status.

In addition, it has been argued that every resident, poor or affluent, benefits from a more equal income distribution (Kawachi et al., 1999); it may not be the absolute levels of neighbourhood socioeconomic disadvantage, as described above, that contribute to health problems (the absolute income hypothesis), but rather that the causal factor is income inequality within a geographical unit (Kawachi et al., 1999). Residents may compare their economic situation with neighbours or others, which may result in stress because these persons are better off or worse off. This has been called the relative income hypothesis (Kawachi et al., 1999).

There is no evidence for an association between income inequality and mental health at the neighbourhood-level (Drukker et al., 2004b) nor between neighbourhood income inequality and mortality as a proxy of general health (Fiscella \& Franks, 1997; Osler et al., 2002). On the other hand, most studies on income inequality at state- or country-level did report associations between income inequality and outcomes, such as perceived health (Kennedy et al., 1998; Soobader \& LeClere, 1999). In addition, two studies including areas with small population sizes as well as areas with large 
population sizes reported a difference in association in these two types of areas (Franzini et al., 2001, Soobader \& LeClere, 1999). Thus, the relative income hypothesis seems applicable only to geographical areas with large population sizes (i.e. large counties or larger) (Wilkinson, 1997; Drukker et al., 2004b; Soobader \& LeClere, 1999). If a large area consists of various small areas that are homogeneous in socioeconomic status (high), this large area can have a high level of income inequality. Therefore, associations between neighbourhood socioeconomic disadvantage and mental health in small areas and associations between income inequality and mental health in large areas are likely to co-occur. One can hypothesize that the reference frame of individuals is not located within small areas, but may be determined nationwide, for example by television. Thus, although there is evidence for what has been called the "absolute" income hypothesis at neighbourhood level, the effects of objective socioeconomic deprivation can also be the result of a person's sense of their status using a reference frame outside the neighbourhood of residence.

\section{CONCLUDING REMARKS AND POLICY IMPLICATIONS}

In sum, after controlling for individual socioeconomic status, there is evidence for an association between neighbourhood socioeconomic status and objective as well as subjective mental health in adults. Evidence for such an association in young children is even stronger.

Nevertheless, in spite of the fact that several studies consistently reported associations, it may be that reported associations between neighbourhood socioeconomic status and objective as well as subjective mental health are the result of social selection; in epidemiological studies, causality can never be proven. Most researchers disentangling neighbourhood socioeconomic status from individual-level socioeconomic status are interested in true contextual effects, rather than compositional effects (social selection). Contextual effects have been defined as true neighbourhood effects, while compositional effects are based on the individual characteristics of the neighbourhood residents (Pickett \& Pearl, 2001; Cullen $\&$ Whiteford, 2001). However, compositional effects and contextual effects are interrelated and not mutually exclusive (Subramanian et al., 2003). People usually evaluate the neighbourhood before buying or renting a house. Thus, theoretically, individuals with similar preferences and characteristics will concentrate in particular neighbourhoods (social selection), and even after con- trolling for known individual characteristics, neighbourhood-level associations may still be (partly) compositional. This also implies that there is a possibility that residual confounding leads to spurious results at the neighbourhood level, because of "omitted variable bias" (Leventhal \& Brooks Gunn, 2000). To put it more simply, families moving into or not moving out of neighbourhoods may differ from their peers in other things than the confounders (e.g. in motivation, literacy etc). This makes it even more difficult to discriminate between true contextual effects and true compositional effects. However, even if the association between neighbourhood socioeconomic status and mental health (service use) is fully explained by individual characteristics, the fact remains that psychiatric patients mainly live in low socioeconomic status neighbourhoods. Furthermore, when disentangling individual from neighbourhood socioeconomic status, this also brings along the risk of over-control for individual-level variables, resulting in underestimations of neighbourhood effects (Sampson $e t$ al., 2002). Thus, even if associations with neighbourhood factors are small, social workers and mental health professionals may focus on disadvantaged neighbourhoods. For example, availability of psychiatric facilities in poor neighbourhoods may be increased, thus raising the level of access to services. For example, a multidisciplinary team of mental health professionals opened an office in a community centre in a disadvantaged neighbourhood in a medium-sized city in the Netherlands (project "Pecunia", Maastricht). This enables people with mental health problems and their healthy neighbours alike in directly contacting staff members. Therefore, access to care is facilitated. Patients are not only helped with their psychiatric problems, but other problems, such as accommodation and finances, are also addressed, so that patients have one contact person taking care of all their problems.

Because social capital has been identified as a likely mechanism why neighbourhood socioeconomic disadvantage is associated contextually with mental health, future research on neighbourhood socioeconomic status should include data on both individual socioeconomic status and data on neighbourhood social capital.

As stated above, it may not be absolute levels of neighbourhood socioeconomic status that are responsible for the association between neighbourhood socioeconomic disadvantage and mental health, but rather relative disadvantage compared to adjacent areas or to a nationwide frame of reference. These factors will need to be taken into account in future work. 


\section{REFERENCES}

Aneshensel C.S. \& Sucoff C.A. (1996). The neighborhood context of adolescent mental health. Journal of Health and Social Behavior 37, 293-310.

Boydell J., Van Os J., McKenzie K., Allardyce J., Goel R., McCreadie R.G. \& Murray R.M. (2001). Incidence of schizophrenia in ethnic minorities in London: ecological study into interactions with environment. British Medical Journal 323, 1336-1338.

Caughy M.O., O'Campo P.J. \& Muntaner C. (2003). When being alone might be better: neighborhood poverty, social capital, and child mental health. Social Science and Medicine 57, 227-237.

Cullen M. \& Whiteford H. (2001). The interrelations of social capital with health and mental health: Canberra, Australia: Commonwealth Department of Health and Aged Care. Retrieved December 8, 2004, from: http://www.mentalhealth.gov.au/resources/inter.htm

Dalgard O.S. \& Tambs K. (1997). Urban environment and mental health: A longitudinal study. British Joumal of Psychiatry 171, 530-536.

De Silva M.J., McKenzie K., Harpham T. \& Huttly S.R. (2005). Social capital and mental illness: a systematic review. Journal of Epidemiology and Community Health 59, 619-627.

Diez Roux A.V., Merkin S.S., Arnett D., Chambless L., Massing M., Nieto F.J., Sorlie P., Szklo M., Tyroler H.A. \& Watson R.L. (2001). Neighborhood of residence and incidence of coronary heart disease. New England Journal of Medicine 345, 99-106.

Dohrenwend B.P., Levav I., Shrout P.E., Schwartz S., Naveh G., Link B.G., Skodol A.E. \& Stueve A. (1992). Socioeconomic status and psychiatric disorders: the causation-selection issue. Science 255 946-952.

Driessen G., Gunther N. \& Van Os J. (1998). Shared social environment and psychiatric disorder: A multilevel analysis of individual and ecological effects. Social Psychiatry and Psychiatric Epidemiology 33 606-612.

Drukker M. \& Van Os J. (2003). Mediators of neighbourhood socioeconomic deprivation and quality of life. Social Psychiatry and Psychiatric Epidemiology 38, 698-706.

Drukker M., Kaplan C.D., Feron F.J.M. \& Van Os J. (2003). Children's health-related quality of life, neighbourhood socio-economic deprivation and social capital. A contextual analysis. Social Science and Medicine 57, 825-841.

Drukker M., Driessen G., Krabbendam L. \& Van Os J. (2004a). The wider social environment and mental health service use. Acta Psychiatrica Scandinavica 110, 119-129.

Drukker M., Feron F. J. M. \& Van Os J. (2004b). Income inequality at neighbourhood level and health-related quality of life, a contextual analysis. Social Psychiatry and Psychiatric Epidemiology 39, 457 463.

Drukker M., Kaplan C.D., Schneiders J., Feron F.J.M. \& Van Os J. (2006a). The wider social environment and changes in self-reported quality of life in the transition from late childhood to early adolescence: a cohort study. BMC Public Health 6, 133.

Drukker M., Kaplan C.D. \& Van Os J. (2006b). Chapter 5: Social capital and quality of life and mental health in Mastricht, The Netherlands; the neighbourhood matters. In Social Capital and Mental Health (ed. T. Harpham and K. McKenzie), pp. 86-108. Jessica Kingsley: London, Philadelphia.

Drukker M., Krabbendam L., Driessen G. \& Van Os J. (2006c). Social disadvantage and schizophrenia: a combined neighbourhood and individual-level analysis. Social Psychiatry and Psychiatric Epidemiology 41, 595-604.

Dunham H.W. (1971). Sociocultural studies of schizophrenia. Archives of General Psychiatry 24, 206-214.

Eaton W.W. (1974). Residence, social class, and schizophrenia. Journal of Health and Social Behavior 15, 289-299.

Faris R.E.L. \& Dunham H.W. (1939). Mental Disorders in Urban Areas: an Ecological Study of Schizophrenia and Other Psychoses. University of Chicago Press: Chicago.
Fiscella K. \& Franks P. (1997). Poverty or income inequality as predictor of mortality: longitudinal cohort study. British Medical Journal $314,1724-1727$.

Franzini L., Ribble J. \& Spears W. (2001). The effects of income inequality and income level on mortality vary by population size in Texas counties. Journal of Health and Social Behavior 42, 373-387.

Giggs J.A. (1986). Mental disorders and ecological structure in Nottingham. Social Science and Medicine 23, 945-961.

Hare E.H. (1956). Family setting and the urban distribution of schizophrenia. Journal of Mental Science 102, 753-760.

Harpham T. \& McKenzie K. (2006). Social Capital and Mental Health. Jessica Kingsley: London, Philadelphia.

Henderson C., Diez Roux A.V., Jacobs D.R., Jr., Kiefe C.I., West D. \& Williams D.R. (2005). Neighbourhood characteristics, individual level socioeconomic factors, and depressive symptoms in young adults: the CARDIA study. Journal of Epidemiology and Community Health 59, 322-328.

Jencks C. \& Mayer S.E. (1990). The social consequences of growing up in a poor neighborhood. In Inner-City Poverty in the United States (ed. L.E. Lynn jr and M.G.H. McGeary). Brookings: Washington D.C.

Jones P., Rodgers B., Murray R. \& Marmot M. (1994). Child development risk factors for adult schizophrenia in the British 1946 birth cohort. Lancet 344, 1398-1402.

Kalff A.C., Kroes M., Vles J.S.H., Hendriksen J.G.M., Feron F.J.M., Steyaert J.G.P., Van Zeben T.M.C.B., Jolles J. \& Van Os J. (2001). Neighbourhood level and individual level SES effects on child problem behaviour: a multilevel analysis. Journal of Epidemiology and Community Health 55, 246-250.

Kasarda J.D. (1993). Urban Underclass Database: An Overview and Machine-Readable File Documentation. Social Science Research Council: New York.

Kawachi I., Kennedy B.P. \& Wilkinson R.G. (1999). The Society and Population Health Reader - Income Inequality and Health. New Press: New York.

Kennedy B.P., Kawachi I., Glass R. \& Prothrow-Stith D. (1998). Income distribution, socioeconomic status, and self rated health in the United States: multilevel analysis. British Medical Journal 317, 917-921.

Leventhal T. \& Brooks Gunn J. (2000). The neighborhoods they live in: The effects of neighborhood residence on child and adolescent outcomes. Psychological Bulletin 126, 309-337.

Lewis G. \& Sloggett A. (1998). Suicide, deprivation, and unemployment: record linkage study. British Medical Journal 317, 1283-1286.

Lorant V., Kampfl D., Seghers A., Deliege D., Closon M.C. \& Ansseau M. (2003). Socio-economic differences in psychiatric in-patient care. Acta Psychiatrica Scandinavica 107, 170-177.

Mäkikyrö T., Isohanni M., Moring J., Oja H., Hakko H., Jones P. \& Rantakallio P. (1997). Is a child's risk of early onset schizophrenia increased in the highest social class? Schizophrenia Research 23, 245-252.

Markowitz F.E., Bellair P.E., Liska A.E. \& Liu J.H. (2001). Extending social disorganization theory: Modeling the relationships between cohesion, disorder, and fear. Criminology 39, 293-320.

McKenzie K., Whitley R. \& Weich S. (2002). Social capital and mental health. British Journal of Psychiatry 181, 280-283.

Osler M., Prescott E., Gronbaek M., Christensen U., Due P. \& Engholm G. (2002). Income inequality, individual income, and mortality in Danish adults: analysis of pooled data from two cohort studies. British Medical Journal 324, 13-16.

Pickett K. \& Pearl M. (2001). Multilevel analyses of neighbourhood socioeconomic context and health outcomes: a critical review. Journal of Epidemiology and Community Health 55, 111-122.

Reijneveld S.A. \& Schene A.H. (1998). Higher prevalence of mental disorders in socioeconomically deprived urban areas in The Netherlands: community or personal disadvantage? Journal of Epidemiology and Community Health 52, 2-7.

Ross C.E., Reynolds J.R. \& Geis K.J. (2000). The contingent meaning of neighborhood stability for residents' psychological well-being. American Sociological Review 65, 581-597. 
Rossi A., Amaddeo F., Sandri M. \& Tansella M. (2005). Determinants of once-only contact in a community-based psychiatric service. Social Psychiatry and Psychiatric Epidemiology 40, 50-56.

Sampson R.J. \& Morenoff J.D. (1997). Ecological perspectives on the neighborhood context of urban poverty: Past and present. In Neighborhood Poverty. Policy Implications in Studying Neighborhoods, Vol. 2 (ed. J. Brooks-Gunn, G.J. Duncan and J.L. Aber), pp. 1-22. Russell Sage Foundation: New York.

Sampson R.J., Morenoff J.D. \& Gannon Rowley T. (2002). Assessing "neighborhood effects": Social processes and new directions in research. Annual Review of Sociology 28, 443-478.

Schneiders J., Drukker M., Van der Ende J., Verhulst F.C., Van Os J. \& Nicolson N. (2003). Neighbourhood socioeconomic disadvantage and behavioural problems from late childhood into early adolescence. Journal of Epidemiology and Community Health 57, 699-703.

Schwartz S. (1994). The fallacy of the ecological fallacy: the potential misuse of a concept and the consequences. American Journal of Public Health 84, 819-824.

Shaw C.R. \& McKay H. (1969). Juvenile Delinquency and Urban Areas: A Study of Rates of Delinquency in Relation to Differential Characteristics of Local Communities in American Cities, Rev. Ed. University of Chicago Press: Chicago.

Silver E., Mulvey E.P. \& Swanson J.W. (2002). Neighborhood structural characteristics and mental disorder: Faris and Dunham revisited. Social Science and Medicine 55, 1457-1470.

Sloggett A. \& Joshi H. (1994). Higher mortality in deprived areas: community or personal disadvantage? British Medical Journal 309, 1470-1474

Snijders T. \& Bosker R. (1999). Multilevel Analysis, an Introduction to Basic and Advanced Modeling. SAGE Publications: London.

Soobader M.J. \& LeClere F.B. (1999). Aggregation and the measurement of income inequality: effects on morbidity. Social Science and Medicine 48, 733-744.

Stafford M. \& Marmot M. (2003). Neighbourhood deprivation and health: does it affect us all equally? International Journal of Epidemiology 32, 357-366.

Subramanian S.V., Lochner K.A. \& Kawachi I. (2003). Neighborhood differences in social capital: a compositional artifact or a contextual construct? Health and Place 9, 33-44.
Tansella M., Bisoffi G. \& Thornicroft G. (1993). Are social deprivation and psychiatric service utilisation associated in neurotic disorders? A case register study in South Verona. Social Psychiatry and Psychiatric Epidemiology 28, 225-230.

Tello J.E., Mazzi M., Tansella M., Bonizzato P., Jones J. \& Amaddeo F. (2005). Does socioeconomic status affect the use of communitybased psychiatric services? A South Verona case register study. Acta Psychiatrica Scandinavica 112, 215-223.

Turner R.J. \& Wagenfeld M.O. (1967). Occupational mobility and schizophrenia: an assessment of the social causation and social selection hypotheses. American Sociological Review 32, 104-113.

Van Berkel-Van Schaik, A.B. \& Tax B. (1990). Naar een standaardoperationalisatie van sociaal-economische status voor epidemiologisch en sociaal medisch onderzoek. Distributiecentrum DOP: Den Haag.

Van der Linden J., Drukker M., Gunther N., Feron F.J.M. \& Van Os J. (2003). Children's mental health service use neighbourhood socioeconomic deprivation and social capital. Social Psychiatry and Psychiatric Epidemiology 38, 507-514.

Warner B.D. \& Rountree P.W. (1997). Local social ties in a community and crime model: Questioning the systemic nature of informal social control. Social Problems 44, 520-536.

Weich S. \& Lewis G. (1998). Material standard of living, social class, and the prevalence of the common mental disorders in Great Britain. Journal of Epidemiology and Community Health 52, 8-14.

Weich S., Twigg L., Holt G., Lewis G. \& Jones K. (2003). Contextual risk factors for common mental disorders in Britain: a multilevel investigation of the effects of place. Journal of Epidemiology and Community Health 57, 616-621.

Wiersma D., Giel R., De Jong A. \& Slooff C.J. (1983). Social class and schizophrenia in a Dutch cohort. Psychological Medicine 13, 141150.

Wilkinson R.G. (1997). Comment: income, inequality, and social cohesion. American Journal of Public Health 87, 1504-1506.

Wilson W.J. (1987). The Truly Disadvantaged: The Inner City, The Underclass, and Public Policy. University of Chicago Press: Chicago, IL.

Xue Y., Leventhal T., Brooks-Gunn J. \& Earls F.J. (2005). Neighborhood residence and mental health problems of 5- to 11 year-olds. Archives of General Psychiatry 62, 554-563. 